ROCZNIKI KULTUROZNAWCZE

Tom/Vol. XI, numer/number $4 \quad 2020$

DOI: http://doi.org/10.18290/rkult20114-2

VÍCTOR MANUEL TIRADO SAN JUAN

\title{
UNA MIRADA A LA ESTÉTICA MEDIEVAL AL CONTRALUZ DE LA ESTÉTICA CONTEMPORÁNEA*
}

\section{1. ¿QUÉ EDAD MEDIA?}

Umberto Eco, pensador itinerante entre el Medioevo y la contemporaneidad, alerta ante ensalzamientos exagerados de la Edad Media. En una interesante conferencia pronunciada en San Gimignano en noviembre de 1983 con el título "Il sogno del Medioevo", se pregunta el pensador italiano qué pueden tener en común el arte contemporáneo con el medieval, ¿podrían entenderse en algo el papa Benedicto XII (Jacques Fournier) y el creador de Star Wars (George Lucas)? En realidad Eco, como muchos otros intelectuales hoy, se sitúa en una posición de un cierto escepticismo - en su caso de tinte popperiano. La posición de Umberto Eco es muy peculiar, pues, me parece que lucha en su interior con una contradicción que le habita y le duele. A muchos contemporáneos les falta un mínimo acercamiento al mundo antiguo en general, lo que les impide de raíz poder desarrollar cualquier conciencia crítica respecto de la 'modernidad', pero Eco conoce bien la Edad Media. Trata así de situarse en una posición que sobre la base del cierto escepticismo que señalábamos, se desmarca tanto de quienes ensalzan el Medioevo como de la vulgar posición denostadora de la Edad Media. Situándose en la línea del pensamiento hermenéutico 'postmoderno' utiliza la metáfora del sueño para reconstruir y valorar lo que considera las interpretaciones

Prof. Víctor Manuel Tirado San Juan, Profesor Numerario - Universidad Eclesiástica San Dámaso en Madrid, Facultad Filosofía, Catedrático de Filosofía Sistemática III (El mundo); e-mail: vtirado@sandamaso.es; ORCID: https://orcid.org/0000-0002-6724-6633.

* Este artículo ha sido escrito en el marco del proyecto de investigación "Recuperación de la estética medieval y diálogo con la estética contemporánea", financiado por la Oficina de Investigación y Relaciones Internacionales de la Universidad Eclesiástica San Dámaso en Madrid.

${ }^{1}$ Nosotros utilizamos la versión revisada: Umberto Eco, "Dieci mode di sognare el Medioevo", en IDEM, Scritti sul pensiero medievale (Milano: Bompiani/RCS Libri, 2016), 1093-1108. 
fundamentales que se han hecho del Medioevo. Con cierta ironía invierte los términos del prejuicio moderno que ningunea la Edad Media como un paréntesis de oscuridad - de adormecimiento de la civilización - entre el mundo clásico y el moderno. Ahora la Edad Media sería la edad 'despierta', y su fin la entrada en el sueño de la nueva civilización que se va tejiendo. A partir del Renacimiento habrían transcurrido "quattro secoli do sogni"; y en estos cuatro siglos de ensoñación, de "rielaborazione notturna", se habrían recreado diez visiones de la Edad Media: 1) El Medioevo como manera $y$ pretexto: "época vista como 'lugar' mitológico en el que revivir personajes contemporáneos"; 2) El medioevo de la interpretación irónica: "el de Ariosto y quizá Cervantes". Época definitivamente pasada sobre la que se ironiza... Medioevo de la nostalgia; 3) El Medioevo como lugar bárbaro: "el del Séptimo sello o el de Fuente de la virgen de Ingemar Bergman... época oscura por excelencia" o el de la tetralogía wagneriana "sueño de barbarie y fuerza bruta triunfante... hasta Frazetta", el de Carlomagno, que apenas sabía hacer la propia firma y que se presta al sueño de la vuelta a un mundo incontaminado (el Hobbit de Tolkien como modelo paradisíaco humano); 4) El Medioevo romántico: "el del castillo derruido... lleno de fantasmas de esposas asesinadas el mismo día de la boda... espacio de ópera"; 5) El Medioevo de la philosophia perennis: "[el imaginado ("soñado")] por el cardenal Mercier ...o E. Gilson... Maritain... Pío XII, con espíritu de Heroic Fantasy mediática del cruzado Wojtyła..., que presenta aspectos de fineza filológica y de dogmatismo antihistórico"; 6) El Medioevo de la identidad nacional, como el de Walter Scott...; 7) El Medioevo carducciano: "soñado por la tercera Italia... (ibidem) propio de los prerrafaelistas, de Ruskin y de Morris... antídoto a la modernidad"; 8) El Medioevo de Muratori y del Rerum italicarum scriptores; visión que según Eco adopta una perspectiva científica, intentando rescatar el Medioevo real a través de la investigación de documentos, acontecimientos históricos y comportamientos, en la tónica de investigadores como Viollet-le-Duc, la iconografía de E. Mâle y la iconología de Panofsky, "fuera de clichés, con su pluralismo y sus contradicciones"4; 9) el Medioevo de la Tradición en el que se situaría el misticismo hebreo, arábigo y de la gnosis, "el del santo Grial, de los caballeros templarios, de la alquimia, de los iluminados de Baviera o de la masonería actual de rito escocés; el desenlace de una sola y continua historia iniciática, acrítico y antifilosófico". Eco es

\footnotetext{
${ }^{2}$ Eco, "Dieci mode", 1093.

${ }^{3}$ Se refiere a Frank Frazetta, pintor e ilustrador de comics con personajes de inspiración medieval.

${ }^{4}$ Eco, "Dieci mode", 1103.
} 
muy crítico con este posicionamiento: "místico y sincrético, adscribe vorazmente a la propia historia intemporal todo lo que no puede ser probado ni falsado"; por fin, 10) el Medioevo que sueñan los milenaristas.

Como decíamos, Eco adopta una perspectiva popperiana respecto de la concepción de la razón, la cual tiene, en mi opinión, dos problemas. El primero es que no es más que una posición tardo-positivista. Popper se da cuenta de los contrasentidos de la propuesta verificacionista del Círculo de Viena, y frente a ella propone el llamado "falsacionismo o racionalismo crítico". Esto quiere decir que, aunque reactivamente, la propuesta popperiana sigue inmersa en el prejuicio positivista: es una propuesta para el método de la ciencia empírico-matemática, dentro del prejuicio antimentafísico que caracteriza una de las derivas modernas. El segundo problema es que, si se quiere dar un alcance universal al falsacionismo, i.e., un alcance filosófico, extendiéndolo más allá de la razón científica a la razón en general, la propuesta de Popper, o bien se niega a sí misma, o bien sucumbe al escepticismo, pues si se sostiene que la razón nunca puede tener certidumbre absoluta de vivir la verdad, o bien al menos vive la verdad de la falsación de alguna propuesta teórica (entonces ya alcanzaría verdades de manera inequívoca, contradiciendo el supuesto de partida), o bien tampoco podría tener certidumbre del incumplimiento de ningún juicio o teoría. Pero, en realidad, la adscripción a este tipo de escepticismo (supuestamente moderado) pende, como decimos, de prejuicios antimetafísicos propios de cierto itinerario moderno, o bien pende de una actitud vital decantada a partir de experiencias personales, y no tanto de la razón. En este sentido llama la atención, que el argumento de Eco para rechazar interpretaciones del medioevo sea que no estarían 'científicamente' fundadas y que, consiguientemente, tendrían más bien un carácter ideológico al servicio de algún fin practico (algún tipo de "reforma" $)^{5}$. Este posicionamiento, típicamente postmoderno, extiende su sospecha y su rechazo, no sólo a las mostrencas ideologías modernas, sino a cualquier propuesta que postule la posibilidad de la filosofía como ciencia primera. Por eso tipifica también Eco de manera sutil la quita interpretación de la Edad Media (según su tipología), como otra ideología más, dogmática $\mathrm{y}$, consiguientemente, peligrosa: aquella sustentada por múltiples pensadores católicos, que postulando el medioevo como lugar privilegiado para el

\footnotetext{
${ }^{5}$ Eco, "Dieci mode", 1105: "habrá que decir con claridad a qué se alude cuando se celebra una vuelta al Medioevo [...] Decir a cuál de los 10 tipos de Medioevo se estaría retornando, significa decir quiénes somos y qué queremos, si simplemente nos estamos divirtiendo, o si queremos comprender o si nos prestamos sin comprender al juego de alguna reforma".
} 
desarrollo de la philosophia perennnis, se afincaría en un "dogmatismo antihistórico" . Por ello, acaba aludiendo de manera más o menos velada - pero en todo caso muy crítica - a esta quinta supuesta 'ensoñación' de la Edad Media, ensoñación que tendría al medioevo por "modelo de una Tradición que por definición siempre tiene razón [...] Y este Medioevo, producto de los mercaderes del absoluto, me da miedo y os invito a desmitificarlo [...] tiene el sentido negativo de una vuelta nostálgica e idealizante, nutrida de pasión en lugar de razón crítica" ". Tradicionalismo, dogmatismo, "mercaderes del absoluto", actitud "pasional” carente de "razón crítica”. ¡Duros apelativos para hombres como Gilson, Maritain, Wojtyła...! Me parece que Eco confunde la crítica a aspectos decisivos de la modernidad con una supuesta pretensión nostálgica e irracional de vuelta idealizante al medioevo. Por mi parte, no creo que ninguna de las personalidades aludidas albergara la absurda pretensión de un regreso a la Edad Media, ni tampoco de una descalificación del mundo moderno y del mundo actual. Al contrario, la puesta en valor de ciertos aspectos de la Edad Media, no sólo es una tarea necesaria para aquilatar la injusta visión negativa que los primeros modernos construyeron sobre la Edad Media, y por lo tanto para, justamente, lograr una visión más cabal de la verdad histórica, sino también una tarea necesaria para promover la crítica de nuestra época y tratar de ganar una conciencia más lúcida sobre nuestra situación actual. Esta es la finalidad del presente ensayo en lo que a la estética se refiere.

\section{ESTÉTICA MEDIEVAL VERSUS ESTÉTICA CONTEMPORÁNEA}

Suele acotarse la Edad Media en el período que va de la caída del Imperio Romano en el siglo V de nuestra era al descubrimiento de América en el siglo $\mathrm{XV}$. Sin embargo, para lo que nos interesa en este ensayo la acotación precisa no es importante, porque se trata de actualizar rasgos fundamentales del espíritu que atraviesa la Edad Media (decantados en la perspectiva estética) y que contrastan con rasgos fundamentales de nuestra actual civilización ${ }^{8}$. Y pre-

\footnotetext{
${ }^{6}$ Eco, "Dieci mode", 1102.

${ }^{7}$ Eco, "Dieci mode", 1105.

${ }^{8} \mathrm{El}$ debate sobre la posible aportación del pensamiento medieval a la estética se ha reavivado después de los trabajos de Edgar de Bruyne, Władysław Tatarkiewicz, Erwin Panofsky, Rosario Assunto y Umberto Eco. Algunos defienden que realmente apenas si existe una estética medieval (Paul O. Kristeller, Albert Speer, Jan Aertsen y Olivier Boulnois), porque ni siquiera habría habido
} 
cisamente uno de estos rasgos es la incardinación casi instintiva de la cultura medieval en la tradición. Ya lo aludía Eco, pero con tintes críticos y negativos. El filósofo español Xavier Zubiri define la tradición como transmisión tradente de sentido, en definitiva la transmisión entre generaciones del modo de estar en el mundo y de hacerse cargo de él. Justamente a este respecto, y hoy más que nunca con la globalización y con determinadas formas de 'pensamiento' — que también se globaliza—, la actual humanidad ilusamente muestra una tendencia a absolutizarse y desmarcarse de toda tradición sobre la base de la idea moderna del progreso. Se postula como una humanidad culturalmente neutra, global, cuyo único pretendido referente sería la racionalidad científica (a la que - ya lo hemos visto palpitar en Eco- se estatuye como 'la' racionalidad).

Efectivamente, la estética medieval, ${ }^{9}$ y en general la filosofía medieval, se hace cargo del pensamiento clásico (el griego y el helenístico) desarrollándolo a través de esos diez largos siglos hasta la irrupción de la modernidad $^{10}$. En este sentido hay una transmisión creadora del pensamiento de la

en la Edad Media una conciencia de las bellas artes. En mi opinión, y este pequeño ensayo trata justamente de ello, estas posiciones se enmarcan justamente en profundos prejuicios de una parte importante del pensamiento contemporáneo. Más ajustada es la posición de John MarenBorn, "Medieval and Renaissance Aesthetics", en A Companion to Aesthetics, ed. Stephen Davies, Kathleen Marie Higgins, Robert Hopkins y Robert Stecker, David E. Cooper (Malden/Oxford: Blackwell, 2009), 22-28. Para un resumen del estado actual de la cuestión, cf. David TorriJos Castrillejo, “Alberto Magno y las bellas artes”, De Medio Aevo 14 (2020): 117-129.

${ }^{9}$ Nos referimos ahora a la 'estética' como momento de la filosofía primera, que examina racionalmente la dimensión estética de la realidad, i.e., la dimensión estética de la naturaleza y la dimensión estética del hombre como creador, como artista; y no a la estética en alguna de las concepciones fragmentarias actuales, ya únicamente como teoría filosófica de la belleza, o únicamente como teoría del arte o simplemente como apoyo teórico a la crítica del arte- por ejemplo, George Dicki, Introduction to Aesthetics: An Analytic Approach (New York: Oxford University Press, 1997), 3 y ss.

${ }^{10}$ Naturalmente que no pensamos que la modernidad sea por esencia algo malo; en realidad, lógicamente forma parte del drama de la humanidad y en particular de la humanidad occidental con sus luces y sus sombras. Por ello, ella misma es deudora, y no sólo por contraposición dialéctica, de la tradición. Pero, justamente, algunas perspectivas dominantes, por su ilusoria pretensión de autonomía y por su obsesión por ser el sujeto absoluto de su destino y su pretenciosa autoevaluación como edad del progreso, la sitúan en una ilusión que, a mi juicio, manifiesta un error metafísico de calado (como digo, se trata además de determinaciones culturales dominantes, que consiguientemente conviven con otras posiciones diferentes de gran interés; entraña, pues, cierto pluralismo aunque no tanto como ella misma cree). No se tata, consiguientemente, de "apocalípticos y/o integrados”, ¡hay más opciones! Por otro parte, aunque la llamada postmodernidad abandera el valor del pluralismo, a mi parecer en ella sigue perviviendo ese dislocado rasgo dominante moderno que denuncio: la pretendida vocación antimetafísica — correlato de la reducción positivista de la razóny la tendencia a postular la autosuficiencia del hombre y del mundo, inseparable también por su 
escuela socrática (del platonismo a través del neoplatonismo, pero también del aristotelismo) acrisolado con el estímulo de la revelación cristiana. Se trata, efectivamente, del encuentro entre el logos griego y el cristianismo, acontecimiento decisivo en la configuración de nuestra civilización, y objeto hoy por hoy de discusión y valoraciones diversas. Mientras que en el contexto de la tradición de la reforma protestante se tiende a valorar la fusión como una adulteración de la fe cristiana ${ }^{11}$, la tradición católica, en cambio, tiende a considerar el logos griego una preparatio evangelica determinada por la providencia divina ${ }^{12}$. En el fondo del asunto late la decisiva cuestión de la relación fe-razón y cómo ella se ha desplegado a partir de ese primer encuentro.

La estética medieval se va configurando a partir de este encuentro. Cristianos y no cristianos tenían algo en común frente al rasgo moderno al que venimos refiriéndonos: la apertura metafísica y una determinación religiosa radical. Precisamente es en este contexto en el que se establecerá la controversia entre las concepciones neoplatónicas, que optan por una suerte de panteísmo emanantista a partir de lo Uno, y la concepción cristiana, que parte de la transcendencia de Dios y del surgimiento del mundo por creación. Sin duda esta es una cuestión decisiva que llega al menos hasta Hegel. Con Zubiri podemos dividir la historia del pensamiento occidental en dos grandes períodos: a) el horizonte griego de la movilidad, abierto por el problema del ser, y con él del cambio, ya que éste presupone un cierto no-ser; y b) el horizonte cristiano de la creación o de la nihilidad, abierto, justamente, por el presupuesto judeo-cristiano de la condición creada del mundo por el designio amoroso y libre de Dios:

[...] Cuanto ha precedido [a la modernidad] forma una sola evolución histórica, desde el helenismo de Plotino a Hegel [...] una larga tradición desde el comienzo del cristia-

parte del prejuicio antimetafísico. Como vamos a ver, estos dos aspectos son centrales en la ruptura con el medioevo y se patentizan de manera muy clara en la estética.

${ }^{11}$ El mismo Martin Heidegger sentencia: "poco a poco [se] empieza a comprender nuevamente la visión de Lutero de que la sistematización dogmática de la teología reposa sobre un 'fundamento' que no viene primariamente de un cuestionar interno de la fe, y cuyo aparato conceptual no sólo es insuficiente para responder a la problemática teológica, sino que, además, la encubre y desfigura". Sein und Zeit (Tübingen: Max Niemeyer Verlag, 1986), § 3, 10.

${ }^{12}$ Una de las posiciones más fuertes al respecto ha sido la de Benedicto XVI. Pienso, en la rotunda defensa que J. Ratzinger hace de la fusión entre el logos griego y la fe cristina (por ejemplo, en el discurso en la Universidad de Ratisbona del 12 de septiembre de 2006: "Fe, razón y universidad. Recuerdos y reflexiones", La Santa Sede, el acceso 28 de diciembre de 2020, http://www. vatican.va/content/benedict-xvi/es/speeches/2006/september/documents/hf_ben-vi_spe_20060912_ university-regensburg.html. 
nismo ha colocado el pensamiento filosófico dentro de los límites en que debe moverse Descartes [... para el cristianismo Dios es el $\lambda$ o $\gamma$ o $\varsigma$ ] en el doble sentido de entendimiento y fundamento, y es el hecho que el pensamiento cristiano comienza a moverse con la afirmación de que Dios es razón entera del mundo, especialmente del hombre [...] De ahí que todo el pensamiento especulativo del cristianismo comience cuando se pregunta en qué consiste ese mundo del que Dios es razón. La pregunta griega: $\tau$ í $\tau$ ò öv (¿qué es el ser?) se transmuta en la pregunta: ¿qué es el mundo? [...] el mundo se encuentra en una cierta relación con Dios y esta relación se ha llamado creación. La creación, como dice Santo Tomás, no es una acción, sino la simple relación por la que todo ente finito tiene la forzosidad de fundamentarse para ser en un ente infinito, que es su Creador. (Summa Theologiae I, c. 45, a 2, 3)

Como vamos a ir viendo, esta clave hermenéutica de los dos grandes horizontes, se muestra enormemente reveladora. Para empezar sugiere la pregunta de qué es lo que ocurre después de Hegel. Esta pregunta creo que hace ver la complejidad que subyace al proceso de la modernidad. No son pocos los pensadores que han señalado el carácter decisivo de Hegel en la historia de la filosofía, quizá porque intentó una nueva síntesis entre el pensamiento griego y el pensamiento cristiano, que incorporaba la dialéctica al mismo tiempo que la perspectiva histórica. Hegel representa el final de un largo proceso del pensamiento. Este final implica también un fracaso, y, por la tanto, la necesidad de un nuevo comienzo. E. Levinas, por ejemplo, también lo interpreta así desde su posición judía. Pero dentro de la tradición cristiana la percepción es similar. El giro que imprime el existencialismo cristiano, Kierkegaard o Unamuno, pero también la filosofía de la acción de Blondel, representan un nuevo intento de desplegar la síntesis entre razón y fe cristiana, invirtiendo - y esto sí que me parece una característica novedosa de cierta modernidad - el orden de la búsqueda. Si el pensamiento medieval, instalado en la fe, parte fundamentalmente de la Revelación ${ }^{14}$, ahora se trata de partir prioritariamente del hombre y del mundo, y a partir de aquí — si es que la razón no se atora en la pura inmanencia mundanal- llevar a cabo la búsqueda de Dios y de la confirmación de la fe. Hay, pues, también dentro de la modernidad una corriente que, poniendo en valor el mundo, la inmediatez de lo concreto y de la experiencia, sin embargo, no renuncia ni a la metafísica ni a la cuestión del Fundamento; es decir, que no se encierra en la

\footnotetext{
${ }^{13}$ Xavier ZuBiRI. Cursos Universitarios II (Madrid: Alianza Ed., 2010). Segunda Parte: Introducción a la Filosofía desde la perspectiva del horizonte de la creación (1932-1933), 95-96.

${ }^{14}$ Pseudo-Dionisio. Los nombres de Dios, en Obras completas (Madrid: BAC, 2007), 5: “de ninguna manera debe uno atreverse a hablar ni a pensar nada sobre la Deidad supraesencial y misteriosa fuera de lo que nos ha sido divinamente revelado por las Sagradas Escrituras".
} 
inmanencia intramundana, ni en una razón reducida positivista y pragmáticamente hurtando la dimensión transcendental. La exageración 'racionalista' de Hegel, para quien el Concepto encierra ya en sí la totalidad de lo que en la realidad va a acontecer como su despliegue, produce precisamente la saturación de una filosofía de la totalidad, que se adscribe el saber absoluto, y con ello el final de la historia, de la filosofía y del arte. Este exceso racionalista se plasma históricamente con el fracaso de la Ilustración. A partir de aquí entra en crisis tanto la metafísica, a la que se concibe como una especie de irredimible y enfermiza tendencia totalizadora de la razón humana - en la línea de la dialéctica Kantiana de la razón - ante la que hay que precaverse (a ello obedece la teoría de las concepciones del mundo -Weltanschauungen - de Wilhelm Dilthey, o el positivismo de Auguste Comte y después del Círculo de Viena junto a la tradición empirista y pragmática anglosajona), como también entra en crisis la fe, necesariamente vinculada, explícita e implícitamente, a la metafísica. En este contexto, el esfuerzo husserliano por recuperar la razón en su integridad va a significar un apoyo fundamental para poder reconstruir nuevamente la filosofía primera sin los excesos constructivos de un sistema totalizante. Naturalmente, también la estética contemporánea, en sus dos sentidos: como estudio de lo estético y como vida estética, se encuentra inmersa en este contexto: se abandona la metafísica de la belleza y el arte a favor de enfoques parciales de lo estético.

Vamos, pues, a traer a colación y a centrar nuestra reflexión en algunos aspectos de la estética medieval y a contrastarlos con otros de la estética actual.

San Agustín es un nexo fundamental en la fusión entre el pensamiento griego y el medieval. Vamos por ello a comenzar comentando un texto suyo que nos va a introducir en el ambiente característico de la estética medieval permitiéndonos seguir las huellas del movimiento histórico de la razón. En la La ciudad de Dios leemos:

Aún dejadas aparte también estas necesidades de obrar, la conveniencia [congruentia numerosa] de todas las partes es tan racional y apropiada [ratio quam decoris] y se corresponde con simetría tan bella [pulchra sibi parilitate] que no se sabría si en la creación del cuerpo se tuvo en cuenta la utilidad más que la belleza [decoris]. Pues, ciertamente, nada vemos en el cuerpo humano que, siendo creado por razón de utilidad, no dé también lugar a la hermosura [...] Hay, en verdad, algunas cosas, de tal modo dispuestas en el cuerpo, que sólo poseen belleza y no uso [...] mientras que de algunas otras se tiene la belleza pero no el uso. Considero, así pues, fácil de entender que en la creación [conditione] del cuerpo se antepuso la dignidad [dignitatem] a la necesidad [necessitati] Y la restante belleza y utilidad [pulchritudo et utilitas] de lo 
creado, concedida por divina largueza, y que al hombre le cabe esperar y recibir, aunque se halle arrojado y condenado [proiecto atque damnato] a estos trabajos y miserias ¿con qué palabras puede determinarse y decirse? Pues la hallamos en la varia y multiforme hermosura [multimoda et varia pulchritudine] del cielo, de la tierra y del mar, en tan abundante y tan admirable esplendor de la luz misma [in ipsius lucis], en el sol, en la luna y las estrellas, en las densas sombras de las selvas, en los colores y aromas [in coloribus et odoribus] de las flores, en la variedad y multitud de parleras y coloreadas aves, en las variadas especies de tantos y tan grandes animales, de los que más son de admirar los más pequeños [minimum] (pues con mayor estupor vemos las obras de hormigas y abejas que los enormes cuerpos de las ballenas); en el grandioso espectáculo del mismo mar cuando se viste de tan diversos colores cual variados ropajes, y es a veces verde, con matices cambiantes, a veces purpúreo, a veces azul ¿Con qué placer, además, lo contemplamos [delectabiliter spectatur] cuando se embravece, surgiendo de ello tanto mayor deleite por cuanto recrea y divierte así al contemplarle sin que lo arroje y sacuda como navegante? ${ }^{15}$

El texto se sitúa en el contexto de una reflexión sobre la 'bondad' de este mundo a pesar de estar caído por el pecado [proiecto atque damnato] y contrastar con el bien pleno de la vida gloriosa hacia la que camina siguiendo las indicaciones de la fe. La caída ha sido grande; el mal hiere a este mundo; y, sin embargo, los dones divinos permanecen. Se trata, pues, de llamar la atención sobre estos bienes que acontecen en la Tierra ${ }^{16}$. Entre ellos está la naturaleza 'racional' del hombre. Es importante darse cuenta de que esta naturaleza racional, aunque reside fundamentalmente en el alma, afecta de manera esencial al cuerpo. Es importante, porque el platonismo tiende a menospreciar el cuerpo (corpus; $\sigma \omega ́ \mu \alpha ; \sigma \alpha ́ \rho \xi)$, y en general, la filosofía griega, la materia ( $\tilde{\lambda} \lambda)$. El cuerpo, pues, aún sometido al desgaste y a la muerte, participa de las cualidades espirituales del alma racional como muestra su propia disposición y estructura fáctica en congruencia con la naturaleza del alma que lo habita ${ }^{17}$. La intuición de la belleza es propia del espíritu, pero sería imposible sin los

\footnotetext{
${ }^{15}$ San Agustín, La ciudad de Dios, vol. II (Madrid: BAC, 1988), XXII, 24, 4-5.

${ }^{16}$ La caída en cristiano es caída de algún lugar más elevado: la virtud. Al perder nuestra civilización la referencia de la trascendencia del 'cielo', la caída se convierte en estructural para el hombre. M. Heidegger lo confirma en Sein und Zeit (SZ): la caída (Geworfenheit) no es caída de ningún lugar, ni caída en ningún sentido moral; por el contrario la existencia 'impropia', 'inauténtica' que esquiva el ser propio ('caída en el mundo' y 'caída en la tradición', en el 'Man'- SZ § 6, 20) es inexorable y consustancial al hombre (SZ $\S 34 \mathrm{~B}, 167)$. Como el ser se desvela a través del hombre que comprende su sentido en su ser-en-el-mundo, lo estético se revela también a través del hombre en la forma más propia del poetizar. Todo queda centrado en el hombre.

${ }^{17}$ San Agustín, La ciudad de Dios, XXII, 24: "Nonne ita sunt in eo loca sensuum et cetera membra disposita speciesque ipsa ac figura et statura totius corporis ita modificata, ut ministerium animae rationalis se indicet factum?"
} 
sentidos corpóreos sobre los que se apoya ${ }^{18}$. Este aspecto es decisivo, porque, como digo, atenuando el espiritualismo platónico tiende a restituir la importancia del cuerpo en la persona humana, lo que, además, es igualmente decisivo para la estética. Es preciso tomar conciencia de que 'estética' viene de $\alpha i \sigma \theta \eta \sigma i \varsigma$, sensación, percepción, es decir, la aprehensión por la que el alma humana encarnada siente las cosas del mundo. En este sentido, gran parte de la estética contemporánea, habiendo tomado un sesgo quizá excesivamente hermenéutico - correlato del arte eminentemente conceptual-, descuida el elemento sentiente inherente a lo estético. En el contexto de la estética medieval a la que Agustín abre, la valoración de lo sensible evita quedarse atrapado en la antropología espiritualista platónica, para la que la belleza 'visible' es un mero medio de acceso a la 'belleza invisible o inteligible'. La sensualidad con la que Agustín describe ese chorro de belleza sensible, que se nos da en los colores, olores, sonidos... nos hace ver que para el hombre, todos los tipos de belleza requieren un momento de encarnación, aunque sólo el espíritu, fundido con los sentidos, sea capaz de contemplarlas.

Además, la relativa armonía entre el cuerpo y el alma - relativa, porque en este mundo el cuerpo está destinado a la corrupción y la muerte, razón por la que la resurrección de la carne es una exigencia de la existencia gloriosa - no es más que otro ejemplo del orden armónico que rige el universo. Efectivamente, para la estética medieval, la belleza es un constitutivo ontológico de las criaturas, que les viene dado por participación de la belleza en sí o belleza ideal. La unidad, que armoniza las partes en el todo congruo de la cosa, lleva a postular una Unidad primordial como origen del cosmos y fundamento de una belleza universal, transcendental, que inhiere en todos los entes. Esta teoría estética de la proporción comienza con los pitagóricos y su postulación de una música, armonía ( $\rho \rho \mu o v i ́ \alpha)$ universal que ordena todo el cosmos, una unidad primordial que enlaza adecuadamente

\footnotetext{
${ }^{18}$ San Agustín, De Trinitate, IX, 6, 10-11: "cuando en mi interior recuerdo un arco bella y proporcionadamente curvado que vi, por ejemplo, en Cartago, una cierta cosa comunicada a la mente a través de los ojos y trasladada a la memoria, produce una representación imaginativa. Pero con la mente veo algo muy distinto, según lo cual esa obra de arte me complace y por lo cual también, si me desagradara, la desaprobaría. Así, pues, acerca de estas cosas sensibles juzgamos según aquella verdad y la vemos con la mirada de la mente racional [...] representándonos, de una manera, en nuestra mente las imágenes de los cuerpos o viendo lo corpóreo mediante el cuerpo, pero captando, muy de otro modo, con la pura inteligencia, sobre el filo de la mente, las razones y el arte inefablemente bello de tales imágenes".
} 
toda la multiplicidad de los entes que componen el universo. ${ }^{19}$ De los pitagóricos pasa a la escuela socrática, ${ }^{20} \mathrm{y}$ de ahí a través del pensamiento helenístico y el neoplatonismo configura una parte sustancial de la estética medieval, llegando también aquí hasta Hegel. ${ }^{21}$

Esta teoría estética de carácter ontológico de la proporción comienza a entrar en crisis con el nominalismo, que en el mundo contemporáneo toma formas distintas de antiesencialismo, ya en la tradición empirista británica, renovada por el pensamiento del segundo Wittgenstein de los juegos de lenguaje y el significado como uso, ya en la tradición nihilista continental (para la que lo estético debe identificarse con la actividad poderosa de engendrar valores), o en la tradición hermenéutica reactivada por Heidegger que inscribe el valor estético en el marco del sentido engendrado por la Sorge que se apropia posibilidades. Sin embargo, en mi opinión, aunque estos paradigmas de pensamiento abren en algunos respectos horizontes interesantes, no logran desbancar algunos de los postulados fundamentales de la perspectiva ontológica realista. La realidad del mundo no es en modo alguno una mera construcción de la mente humana, ni, consiguientemente, lo es el conocimiento teórico, ni la experiencia ética ni la estética. Dicho de otro modo, la realidad no es mero sentido tejido por la subjetividad humana, aunque, ciertamente, sobre la base de la realidad dada, la subjetividad engendra sentido. Por ello la propuesta de la estética medieval reviste el mayor interés y debe tomarse completamente en serio.

${ }^{19}$ Anthelme Chaignet. Pythagore et la philosophie pythagoricienne. Contenant les fragments de Philolaüs et Archytas (Paris: Diedier et Cie, 1873), 129 y ss.

${ }^{20}$ Platón ya en su juventud postula la armonía como esencia de la belleza (primera hipótesis de Sócrates en la segunda parte de Hipias mayor, 393 c: "lo bello es lo adecuado en sí, no lo adecuado para algún fin". En la República la belleza de la obra de arte es caracterizada como la "perfecta adecuación entre ritmo, armonía y dicción"; y, a la postre, en su armonía con el alma que la crea o la contempla (República 400 e). También Filebo 26 a. Análogamente en Aristóteles, Metafísica 1078 a 36-37: "Las principales especies de lo bello son el orden ( $\tau \dot{\alpha} \xi 1 \zeta)$, la simetría ( $\sigma u \mu \varepsilon \tau \rho i ́ \alpha)$ y la

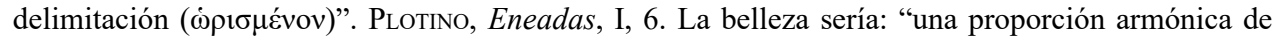
las partes entre sí y con el todo, con la adición de un colorido agradable [...] la belleza de todas las cosas sin excepción consiste en ser simétricas y armónicamente proporcionadas". Trad. esp.: Plotino, trad. de Agustín López y María Tabuyo (Barcelona: El Barquero, 2007, 25-26.

${ }^{21}$ Georg Wilhelm Friedrich Hegel, Estética, trad. De Hermenegildo Giner de los Ríos (Barcelona: Alta Fulla, 1988), 22: "El arte nos ofrece en una imagen visible la armonía realizada de los dos términos de la existencia, de la ley de los seres y de su manifestación, de la esencia y de la forma [...] Lo bello es la esencia realizada, la actividad conforme con su objeto e identificada con él; es la fuerza que se despliega armónicamente a nuestra vista en el seno de las existencias y que borra por sí misma las contradicciones de la naturaleza: dichosa, libre, llena de serenidad aún en medio del sufrimiento y del dolor [...] El bien es el acuerdo buscado; lo bello, la armonía realizada". Y un poco más adelante, nos dice: "Lo bello se define, pues, como la manifestación sensible de la idea". 
La tradición judeo-cristiana acoge críticamente las propuestas de la tradición platónica y neoplatónica y de la tradición de la filosofía hilemórfica aristotélica con los postulados de la fe. Por ejemplo, tenían siempre presente la sentencia del Libro de la Sabiduría: "Tú todo lo dispusiste con número, medida y peso" 22 . Ciertamente la fe va a ser un revulsivo que conmociona la recepción del pensamiento griego. Toda la fuerza del pensamiento platónico reside en el asombroso descubrimiento de lo absoluto, aquello de lo que participan todas las cosas finitas, y, por lo tanto, relativas: un bello cántaro no es tan bello como una bella yegua, y una bella yegua no lo es tanto como una mujer joven bella; cualquier realidad finita es bella o fea según con lo que se la compare, por consiguiente, ni el cántaro, ni la yegua, ni la joven son la esencia de la belleza o la belleza en sí, sino meras participaciones relativas de la Belleza en sí o la Belleza misma. ${ }^{23} \mathrm{La}$ argumentación platónica es enormemente sólida y no se disuelve fácilmente con la acusación de conceptismo o con su reducción a meros juegos de lenguaje. A mi parecer ello no hace sino ocultar el problema, supeditar lo primario y fundamental (en este caso la experiencia originaria de lo bello anclado en entes del mundo) a algo más derivado y subalterno (el lenguaje como institución social). Por eso la estética medieval trabaja sobre la estructura del pensamiento

${ }^{22} \mathrm{Sb} 11,20$. Por ejemplo, San Alberto traduce ontológicamente la sentencia. Todo cuanto existe participa del bien. La forma más básica [diminitum] de bien sería el número, que da a la materia informe su primera distinción. Cada ente tiene una medida, que determina el contorno de la forma [segundo grado de bondad: perfectum]. El peso es la consistencia de la cosa, que se sedimenta en su masa [último grado de bondad: complutum].

${ }^{23}$ Platón. Hipias mayor, 284 c 4. Vemos cómo se traduce esto en la estética medieval; por ejemplo en Alberto Magno, Comentario a "De los nombres divinos" de Pseudo-Dionisio Areopagita, $\S 73,183$ a $28-83$ b 2: "en la causa primera no se han de separar la belleza y lo bello, como si ahí hubiera una cosa que fuese bella y otra que fuese la belleza [...] en las cosas existentes, es decir, en aquellas cosas que poseen el ser en otro o recibido de otro (en efecto, se dice 'existente' [existens] como si fuera 'consistente por otro' [ex alio sistens], de acuerdo con Ricardo de san Víctor" (traducción de David Torrijos en el marco del proyecto de investigación "Recuperación de la estética medieval y diálogo con la estética contemporánea", financiado por la Oficina de Investigación y Relaciones Internacionales de la Universidad Eclesiástica San Dámaso). La unidad compacta o simplicidad de Dios es propia de la Realidad Absoluta que es en sí misma y que no proviene de otra, por contraposición a las realidades creadas, o "cosas existentes". Esto ha sido muy importante en el pensamiento de Zubiri. El tema de sistit extra causas, que se relaciona con la condición ab-soluta (relativamente absoluta), suelta-de, del hombre o con la condición extramundana del Dasein en Heidegger. Al salir de Dios con la creación, podemos decir que las criaturas son extra Deum, son ex-sistentes: sistit ad extra; y esto quiere decir que no tienen su ser en sí mismas sino fuera de sí en el Fundamento al que remiten. Esto se vuelve a plantear en perspectiva fenomenológica en términos de donación tal y como lo enfoca Jean-Luc Marion: el don ha de tener una fuente, que no procede a su vez de una donación extrínseca, sino intrínseca. Serían las procesiones intratrinitarias. 
socrático (platónico-aristotélico) y lo funde con las indicaciones de la revelación cristiana. La belleza esencial comparece en la belleza relativa de los entes del mundo, pero la excede y la precede. Si la belleza es la armónica proporción entre las partes que constituyen la cosa, i.e., lo que las aúna en una esencia clausurada, esta fuerza unificadora ha de venir de 'fuera', pues no puede quedar encerrada en la individualidad no compartible de los entes concretos. En este punto confluyen cristianos y neoplatónicos. Pero, ¿qué es este 'afuera'?

Unidad y pluralidad, tierra y cielo, visible e invisible, corruptible y eterno, participante y participado, lo generante y lo generado..., estas polaridades constituyen la estructura sobre la que se erige la discusión. Por el contrario, como una inusitada ruptura, va constituyéndose en nuestra cultura moderna otro dinamismo contrario, el cual niega la polaridad tierra/cielo, Dios y mundo, contingente, necesario, etc., pensamiento al que, quizá como nadie, da voz el nihilismo de Nietzsche. La 'Tierra' queda sumida en una infinita soledad. La riqueza de los transcendentales se ve reducida a la paupérrima simplicidad de la voluntad de poder. Quizá nunca como hoy haya caído la humanidad en un estado tan deficitario de metafísica. La reflexión de Plotino, Proclo, Jámblico, Porfirio... y los pensadores cristianos que dialogan con ellos, fue enriqueciendo la especulación metafísica y obligando al pensamiento cristiano a profundizar en la propia revelación. Frente a la diseminación en que vive parte del pensamiento actual (tendencia a la fragmentación en muchos órdenes de la vida), la filosofía medieval va entreverando su especulación en un diálogo progresivo con la filosofía alternativa en un proceso continuo de contrastación intersubjetiva, que con sus intermitencias, se prolonga efectivamente hasta Hegel. Este intenso diálogo filosófico pone de manifiesto, sobre un cierto fondo común compartido, las fundamentales diferencias (de aquí la intensidad del conflicto entre las diversas posiciones que habitan este período de inicio de la alta Edad Media). Umberto Eco ve con sospecha esta 'dialéctica', porque genera 'herejías', y tendría razón si es que la diferencia se dirime con violencia (lo que a menudo ocurre); pero, esto no obvia la ineludible necesidad de buscar afanosamente la verdad, y por lo tanto, de confrontarse con las propuestas metafísicas alternativas. La pretensión tan extendida hoy de que pensar con radicalidad las cuestiones, i.e., elaborar la filosofía primera, es un ejercicio de dogmáticos intolerantes no es más que la excusa de una cobarde hipocresía existencial, que, en todo caso, no hace sino esconder sus propios presupuestos metafísicos, a menudo muy pobres. 
San Agustín, el pensamiento medieval cristiano, el cristianismo, sostiene con fuerza que este mundo, y la caída que lo oprime, no es lo definitivo. $\mathrm{Y}$ frente al eterno retorno griego en el que las relaciones entre el cielo y la tierra, entre Dios y el hombre, se repetirían eternamente, el cristianismo cree en un decurso histórico temporal con un principio y un fin, es decir, en un final apoteósico (i.e. de deificación) del drama humano y del mundo en el que el hombre queda definitivamente deificado, i.e., integrado a la vida trinitaria ("Pues sabemos que la creación entera gime y sufre hasta ahora dolores de parto" ${ }^{24}$ ). Mientras que para el platonismo la experiencia estética de la belleza visible, i.e., sensible, no es más que un tránsito intermedio para acceder a la contemplación de la belleza invisible, i.e., intelectual, para el cristianismo esto no puede ser así, pues el cuerpo forma parte indisoluble de la esencia humana ${ }^{25}$. Esto quiere decir, a mi entender, que cumplida la deificación del hombre en la vida gloriosa, la experiencia humana de la belleza tendrá que seguir aconteciendo en la forma humana, esto es, sentientemente. El cuerpo glorioso no deja de ser cuerpo, por lo que, en algún sentido, la 'belleza visible' seguirá siendo imprescindible, en sí misma, y también como vehículo de la belleza invisible. Agustín mantiene aquí una encarnizada lucha, que ha sido remarcada por alguno de los más eminentes estudiosos $^{26}$. En todo caso, brilla en él, no sólo el canto a la belleza del mundo, que es la belleza de la armonía, i.e., de la unidad congrua de las partes que constituyen la unidad indivisa de los entes, sino también el canto a la excelencia y dignidad del hombre. Llama la atención, y contrasta con la cultura actual, la diafanidad con la que distingue lo pragmático y utilitario de lo bello, y llama particularmente la atención la mirada agustiniana — que va a atravesar el medioevo-, una mirada 'especulativa', es decir, una mirada contemplativa, que sabe distanciarse de la realidad y simplemente mirarla, esto es, abandonarse a lo que ella $d a$. Cae entonces en la cuenta, no solo de que utilidad y belleza no se contraponen entre sí ("no se sabría si en la creación del cuerpo se tuvo en cuenta la utilidad más que la belleza"), sino de que la realidad está dotada de valores estéticos que no obedecen a ninguna

\footnotetext{
${ }^{24} \operatorname{Rm} 8,23$.

${ }^{25}$ Étienne Gilson. El espiritu de la filosofía medieval, trad. de Ricardo Anaya Dorado (Madrid: Ediciones Rialp, 2004), 183.

${ }^{26}$ Karel Svoboda, La estética de San Agustín y sus fuentes, trad. de Luis Rey Altuna (Madrid: Agustinus, 1958). También, Robert J. O'Connell, Art and the Christian Intelligence in Saint Augustin (Cambridge: Harvard University Press, 1978); también en: Agostino Trapé, San Agostino. L'uomo, il pastore, il mistico (Fossano: Edizione l'Esperienze, 1976). Defiende lo contrario, Augustin UÑa Juárez, Cántico del universo. La estética de San Agustín (Madrid: Universidad Complutense de Madrid), 1999.
} 
utilidad ("hay, en verdad, algunas cosas, de tal modo dispuestas en el cuerpo, que sólo poseen belleza y no uso"). Kant, en la magnífica descripción fenomenológica que hace en la Crítica del Juicio de la experiencia de la belleza (juicio reflexionante estético) subraya este carácter desinteresado que lo específica, y que diferencia inexorablemente la experiencia estética de cualquier otra experiencia humana (al margen de la religiosa y habrá que ver lo que concierne a la pura contemplación teórica de lo real y la contemplación pura del bien), la cual sitúa al hombre en un éxtasis que ya no quiere nada es desinteresada por esencia- salvo, retroactivamente, seguir experimentando la belleza ${ }^{27}$. Pero respecto a las implicaciones metafísicas que puedan inferirse de este deleite estético inherente a la "finalidad sin fin" que le es propio, Kant mantiene a mi juicio un angustioso silencio. ¿Qué sentido puede tener este placer que experimentamos en el libre juego de las facultades de conocer ante determinadas representaciones sensibles? ¿Es simplemente un factum y ya está? Todo lo contrario al compromiso metafísico de la estética antigua y medieval. Si nos complacemos en la belleza de las cosas, es porque la Unidad primigenia que armoniza todo y a nosotros mismos, comparece en ella de forma misteriosa, pues no se ve con los 'ojos', sino, sobre su base, con el 'alma' (visio mentis).

Es verdad que la estética contemporánea ha enriquecido y ampliado la perspectiva de la belleza. La ampliación de horizontes que ha llevado a cabo el arte contemporáneo con las sucesivas vanguardias, desde el surgimiento del arte figurativo abstracto a los ready-mades o al arte pop..., parece haber sentenciado a muerte el enfoque ontologista de la estética clásica y medieval, a la que se tiende a considerar ingenua y dogmática. No habría ningún canon universal fundado ontológicamente. Los valores estéticos serían enteramente producciones históricas de la cultura... y, consiguientemente, la teoría de la proporción habría quedado definitivamente superada. En mi opinión, no es así; ha sido, ciertamente, enriquecida e iluminada, pero no refutada. Artur Danto da, a mi juicio, claves para entender lo que digo. En su obra El abuso de la belleza ${ }^{28}$, parece extremar incluso el antiesencialismo de Wittgenstein. Como es sabido, la crítica de Wittgenstein al esencialismo clá-

\footnotetext{
${ }^{27}$ Immanuel KANT, Crítica del juicio, trad. de Manuel García Morente (Madrid: Espasa Calpe, 1981), 102-103: "cuando se trata de si algo es bello, no quiere saberse si la existencia de la cosa importa o puede importar algo a nosotros o a algún otro, sino de cómo la juzgamos en la mera contemplación (intuición o reflexión) [...en el juicio de gusto estético] se quiere sólo saber si esa mera representación del objeto va acompañada en mí de satisfacción, por muy indiferente que me sea lo que toca a la existencia del objeto de esa representación"

${ }^{28}$ Arthur DANTO, El abuso de la belleza: La estética y el concepto del arte (Barcelona: Ediciones Paidós, 2011).
} 
sico y su teoría del 'parecido de familia' orientó las investigaciones de los pensadores analíticos sobre lo que pueda significar el concepto 'arte'. La tesis de Wittgenstein es que, aun sin definición esencial de un concepto, es posible establecer una serie de criterios que permitan decidir si algo cae o no bajo un concepto. Pero esto fracasó en el caso de los ready-mades y en el caso del inventario de Fluxus (la obra de George Brech Valoche - a Flux Travel Aid-1975). Algunos pensadores propusieron que también en las obras que no pretenden tener nada de belleza hay belleza, como por ejemplo en "Fuente" de Duchamp (Arensberg pensaba que el sentido de esta obra estaba en revelar la belleza que ya había en el urinario fabricado). Lo mismo ocurriría con "caja de brillo" de Warhol. Sin embargo, la tesis de Danto es que la belleza que pueda haber en estas obras no es esencial, sino secundaria: "Digamos que los partidarios de Duchamp pensaban que la belleza era interna a la obra, mientras que muchos otros, entre los cuales me encuentro, creemos que es secundaria. Pero lo que no admite dudas es que la obra fue, por muchas razones, disonante. De ahí que pueda aparecer tanto en una exposición sobre la disonancia o, con la misma facilidad, en otra que se titule Regarding Beauty" 29 . Incluso, piensa Danto, habría obras en las que "la belleza [estaría] internamente relacionada con la disonancia"; es decir, es bella porque es disonante, y es disonante porque es bella. Y apunta a ejemplos de artistas más ligados a los ataques conservadores contra el National Endowment of the Arts, como Robert Mapplethorpe o Andrés Serrano (podríamos incluir a otros como los artistas que participaron en la exposición de la Royal Academy de Londres en 1997 Sensation: Young British Artists From the Saatchi Collection, Marcus Harvey, Chris Ofili... u otros artistas pertenecientes a contextos distintos, como por ejemplo Damian Hirst). En todo caso, la tesis de Danto es que para explicar el valor estético de todo este conjunto de obras del arte contemporáneo habría que postular una "segunda belleza": la que surge de la relación del objeto con el espíritu (del creador y del contemplador). El ready-made, originariamente y por esencia, era lo contrario a una obra de arte, un utensilio; sin embargo, en el contexto conceptualista de Duchamp, que justamente quiere reflexionar plásticamente artísticamente - sobre si un objeto ya fabricado con fines pragmáticos puede convertirse en obra de arte, la misma cosa adquiere una 'belleza' añadida; hecho que quiere significar la firma que Duchap imprime sobre el urinario ${ }^{30}$.

\footnotetext{
${ }^{29}$ DANTO, El abuso, 44-45.

${ }^{30}$ Jean-Luc Marion interpreta esto como una prueba de la insuficiencia de la metafísica sustancialista; la 'cosa' material concreta dejaría de tener relevancia para la donación de la 'belleza'. Yo creo, sin embargo, que aunque, ciertamente estas formas artísticas de la vanguardia sitúan cada vez
} 
Duchamp apela a la tesis de Hegel sobre el valor añadido de la belleza de las artes humanas, porque "habría nacido dos veces del espíritu". Estoy de acuerdo con Duchamp, en el sentido de que, efectivamente, el hombre amplía el ámbito de la belleza ontológica de los entes del mundo hacia unas nuevas realidades que podríamos llamar "eventos", es decir, acontecimientos de la vida del espíritu, que ellos mismos pueden ser bellos, de una 'belleza invisible'. Pero esto no niega en modo alguno la teoría de la proporción, simplemente la amplía ${ }^{31}$. Esto se entiende muy bien desde la ontología de Zubiri; hay dos tipos de 'cosas': cosas-realidad y cosas-sentido. La estética medieval se centra fundamentalmente en el valor estético de las primeras; la contemporánea, debido a la centralidad que ha tomado el hombre mismo, en el valor estético de las segundas, i.e., de los eventos. Las cosas-reales son físicas,

con mayor intensidad el valor estético en el sentido, la cosa sigue siendo importante; al final está la pintura concreta de las latas de sopa Campbell o el urinario de Duchamp. A mi parecer hay que mantener una cierta primacía de la donación sensible en el sentido de que las demás donaciones en la vida de conciencia humana necesitan de uno u otro modo apoyarse sobre ellas. Precisamente la fenomenología genética muestra esta arquitectura de la conciencia. Esto pende de que, en todo caso, el hombre también pertenece al mundo, en lo que su condición corpórea juega una papel decisivo. Ciertamente, el hombre es también un ser-en-el-Mundo, lo cual implica que la vida gloriosa tiene que reasumir el mundo en algún sentido, y ese es el significado de la resurrección. Jean-Luc MARION, Étant donné. Essai d'une phénoménologie de la donation (Paris: PUF, 1997), 63: "El cuadro, pues, no aparece en tanto que subsiste. Una contraprueba patente viene de los ready-made: hacen visible en segundo grado un objeto constituido.... ya según una nueva visibilidad (la de la obra) sin modificar nada de la subsistencia originaria... lo que ha cambiado es su puesta en escena... pues la nueva visibilidad no pende de la subsistencia de los materiales (ya hechos, prefabricados en el objeto útil) sino de la irrealidad del montaje, del puro 'hacer-ver' y 'querer-ver', por definición no subsistente, cambiante... un ready-made no conquista su fenomenalidad más que contra su material subsistente [... esto se aplica al cuadro vulgar y hasta a todo lo que aparece] el cuadro (y con él fenómeno de la visibilidad común) no se reduce a una subsistencia". Más adelante (69): "Rechazamos que la belleza sea. El cuadro no aparece bello a la medida de lo que es, sino, por el contrario, sin proporción, a saber, independientemente de su onticidad". Y aludiendo al problema alumbrado por Walter Benjamin (Das Kunstwerk im Zeitalter seiner technischen Reproduzierbarkeit. 34. Aufl. (Frankfurt am Main: Suhrkamp, 2015), 70) en relación a las reproducciones de obras de arte: „la obra permanece la misma incluso cuando el soporte cósico desaparece (en la restauración) o se multiplica (en las reproducciones)" (la traducción al español es mía).

${ }^{31}$ El propio Danto (El abuso, 51), en cierto modo lo reconoce: "Aunque la belleza hubiera demostrado ser mucho menos esencial para las artes visuales de lo que la tradición filosófica había imaginado, eso no quería decir que no fuera esencial para la vida humana [...] la necesidad de la belleza en los momentos extremos de la vida está profundamente arraigada en lo humano (... pero) la belleza es solamente una cualidad estética entre un inmenso abanico de cualidades estéticas, y la estética filosófica estaba en un callejón sin salida por haberse concentrado demasiado en la belleza. Sin embargo, la belleza es la única cualidad estética que también es un valor, como la verdad y la bondad. Y no simplemente uno de los valores que nos permiten vivir: es uno de los valores que definen lo que significa una vida plenamente humana”. 
están determinadas materialmente en el espacio-tiempo y son perceptibles por los sentidos. Las cosas-sentido pertenecen al sentido que las cosas-reales del mundo cobran en la 'vida' del hombre, es decir, son de índole conciencial. Pero dado que toda cosa-sentido tiene que apoyarse en cosas-reales (acabamos de decir que una cosa-sentido consiste en el sentido que una cosa real adquiere en el contexto de la vida humana; por ejemplo, el agujero en la roca se convierte para el hombre que lo usa como vivienda en la cosa-sentido "hogar o morada" ${ }^{32}$ ), la segunda estética no puede ser independiente de la primera; lo que en el fondo quiere decir, que la vida del espíritu humano, efectivamente, se teje en el mundo de los entes ${ }^{33}$. Así las cosas: el enfoque propio de una ontología realista como el de la estética medieval está veladamente a la base del enfoque hermenéutico de la estética contemporánea.

Con una concepción ontológica aparentemente similar a la del neoplatonismo $^{34}$, pero concebida según la dogmática cristiana, Pseudo-Dionisio Areopagita plantea el problema de la naturaleza de Dios, Principio de todo. Lo hace con ese género típico de la teología medieval que inquiere qué nombres pueden atribuirse adecuadamente a Dios, es decir, con qué logos podemos alcanzar la esencia divina de los nombres de Dios. Entre los "nombres" que de alguna manera cabe aplicar a la Realidad divina está el de la Hermosura o Belleza $a^{35}$ : "llamamos Hermosura a aquel que trasciende toda belleza, porque Él reparte generosamente toda belleza a todos los seres, a cada uno según su capacidad y por ser causa de la armonía y belleza de todo". ¿Cómo lo sabemos? Pseudo-Dionisio es un ejemplo destacado de cómo la Edad Media vive inmersa en una concepción del acceso al ser, y a Quién, siendo su principio generador, estaría quizá allende el ser mismo, y que, consiguientemente, desborda cualquier conceptuación estrecha de la razón. Por un lado, Dios es en sí mismo inaccesible: "la Eternidad supraesencial transciende las esencias, e igualmente la Unidad, que está sobre toda inteligencia, trasciende

\footnotetext{
${ }^{32}$ Xavier ZuBIRI, Sobre la esencia (Madrid: Alianza Editorial \& Fundación Xavier Zubiri, 2008), 104-109, 230, 290-292.

${ }^{33}$ Aquí se muestra la diferencia entre la fenomenología realista de Zubiri y otras propuestas fenomenológicas (como, por ejemplo, de la Michel Henry), pues aunque la realidad no se restringe en Zubiri a la realidad del mundo (ni a ninguna 'zona' en concreto, pues es transcendental y consiguientemente abre también a 'la' realidad divina), en el caso del hombre la realidad mundana tiene un carácter fundamental. Creo que por eso la propuesta del pensador español encaja mejor en la tradición del pensamiento occidental, a pesar de las críticas que él mismo le dirige.

${ }^{34}$ En Plotino: 1) La Unidad: Supra-Ser transcendente (Verdad-Bien-Belleza); 2) La Unidad misma que se autopropone; 3) La Inteligencia (Mundo inteligible de Ideas); 4) Alma del mundo (formación del mundo sensible); 5) Mundo sensible (materia).

${ }^{35}$ Pseudo-Dionisio, Los nombres de Dios, en Obras completas (Madrid: BAC, 2007), 36.
} 
a todo entendimiento. Y el Uno inescrutable queda incomprensible a todo razonamiento [... es, pues,] sin nombre, no corresponde a nada de lo que existe [...] no existe vestigio alguno por donde penetrar en su secreta infinitud" ${ }^{\prime 3}$. Sin embargo, a pesar de esta inalcanzable trascendencia, siendo como es "la causa del ser en todo [...] este Bien no está totalmente incomunicado con todos los seres, sino que por sí mismo manifiesta generosamente a todos aquel firme Rayo supraesencial que le es propio y constante con iluminaciones convenientemente apropiadas a cada uno de los seres y de esta manera atrae hacia sí a las almas santas para que, en la medida posible, le contemplen, se unan a Él y le imiten". Así, pues, por infinita que sea la distancia entre el Fundamento y el mundo, ambos están esencialmente comunicados: la Realidad divina, fundando (creando) el mundo, con su "Rayo supraesencial"; el mundo, constituyéndose desde la Realidad divina que lo engendra, es decir, siendo respectivamente a él. ${ }^{37}$ Este intrínseco, constitutivo y constituyente nexo entre Fundamento y realidad fundada es el que abre la posibilidad del acceso del hombre a un cierto conocimiento racional de Dios (a parte, naturalmente, de otras posibles revelaciones libres suyas), un 'conocimiento' por vía analógica, usando:

símbolos apropiados ... a las realidades divinas y a su vez por éstos, según nuestra capacidad, tendemos hacia la verdad simple y una de las contemplaciones inteligibles. Y dejando atrás nuestros naturales pensamientos de las cosas divinas, dirigimos todas nuestras fuerzas intelectuales, en la medida en que nos es permitido, hacia el

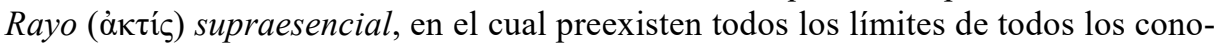
cimientos de una manera sumamente inefable. Rayo que ni es posible imaginar, ni expresar con palabras, ni, resumiendo, poder contemplar de algún modo, pues excede todas las cosas y no se lo puede conocer (...pues) si, efectivamente, todo conocimiento se refiere a los seres, y tiene su fin en los seres, el que es superior a todo ser, está también fuera de todo conocimiento ${ }^{38}$.

El texto, que, en realidad, y en sintonía con el pensamiento neoplatónico, reproduce el itinerario que Platón había descrito en el Fedro para el alma que se eleva a través de las 'bellezas visibles' hasta llegar a contemplar "lo Divino mismo", la Belleza en sí invisible que "habita el lugar supraceleste... a la espalda del cielo" 39 , representa el modo medieval de conciliar fe y razón mediante una concepción 'amplia' de los modos de acceso a 'lo otro': por intelección sentiente en lo concerniente a los seres del mundo, por la visio-

\footnotetext{
${ }^{36}$ Pseudo-Dionisio, Los nombres de Dios, 6.

37 "Respectividad" es la índole propia de la comunicación formal, real, entre las realidades en términos del Xavier Zubiri.

${ }^{38}$ Pseudo-Dionisio, Los nombres de Dios, 9-10.

${ }^{39}$ Platón, Fedro, 247 c.
} 
mentis en lo concerniente a las Ideas o Arquetipos... y mediante simbolos para acceder analógicamente a Dios. Esta es una cuestión decisiva y de plena actualidad. Una de las aportaciones fundamentales de la fenomenología de Husserl - y a partir de él, de otros fenomenólogos - ha sido hacernos ver la pluralidad de actos intuitivos de los que la conciencia es capaz. Ya en las Investigaciones lógicas escudriña Husserl las diferencias entre la intuición sensible y la categorial. El decurso de esta prospectiva ha llegado hasta filósofos actuales como Jean-Luc Marion o también Xavier Zubiri. Para Marion, el modo adecuado de poner en practica la reducción fenomenológica viene indicado por su eslogan: "tanta reducción, tanta donación" se trata de reducir las construcciones teóricas con que la conciencia vela las donaciones originarias, y en tal caso se abren ante nosotros múltiples modos distintos de donación ('intuición'); entre ellos la donación propia de la experiencia estética, que no es reducible a ningún tipo de experiencia teórica; o en Zubiri, por ejemplo, el modo esencialmente distinto de darse las "realidades-objeto" a como se da la "fundamentalidad de la realidad" (la formalidad de realidad), pero también las diferentes maneras como la realidad se actualiza en la voluntad o el sentimiento ${ }^{41}$. Precisamente la dimensión estética de la realidad es accedida por el sentimiento y no propiamente por la inteligencia. Kant lo barrunta ya en la Crítica del Juicio, cuando sitúa el juicio estético como un tipo de juicio reflexionante, es decir, que no parte de un principio dado apriori, sino que él se da a sí mismo el principio a partir del sentimiento interior (deleite estético) en el despliegue progresivo de la experien$\mathrm{cia}^{42}$. Por ello nos alerta contra la pretensión de que alberguemos en nosotros una 'idea' de belleza que la inteligencia pueda definir ${ }^{43}$. Desde luego, esto

\footnotetext{
${ }^{40}$ Jean-Luc MARION, Essai d'une phénoménologie de la donation (Paris: PUF, 1997), Libro I, $\S 1$, "Cuestiones de principio", 20 y ss.

${ }^{41}$ El 'sentimiento', no en el sentido 'subjetivista' moderno, que lo concibe como una afección interna de una conciencia cerrada sobre sí., sino como una facultad respectiva, que actualiza a su manera lo real. En una dirección similar apunta la estimativa de Max Scheler o de Ortega en su teoría de los valores.

${ }^{42}$ KAnT, Kritik der Urteilskraft. Einleitung 4 (p. 78 de la edición española): "El Juicio, en general, es la facultad de pensar lo particular como contenido en lo universal. Si lo universal (la regla, el principio, la ley) es dado, el Juicio que subsume en él lo particular (incluso cuando como Juicio transcendental pone a priori las condiciones dentro de las cuales puede subsumirse en lo general), es determinante. Pero si sólo lo particular es dado, sobre lo cual él debe encontrar lo universal, entonces el Juicio es solamente reflexionante". También en el "Momento III": Relación: (p.132 de la traducción española): "el prototipo del gusto es una mera idea que cada uno debe producir en sí mismo".

${ }^{43}$ Este punto es, sin duda, difícil a la vez que importante. No niega que haya una teleología, pero es una teleología que se actualiza existencialmente y no por una especie de canon preciso al modo de ideas delimitadas o esquemas numéricos matemáticos.
} 
plantea importantes interrogantes al modo como la estética medieval plantea el problema la belleza desde Platón, como si la idea de Belleza fuese una Idea (correlato de un concepto preciso) emborronada por el olvido provocado por la caída en el cuerpo (o por la distancia de Dios en el cristianismo medieval). Me parece que aquí hay que ampliar también la idea de 'perfección' vinculada al carácter acabado de la unidad que reúne congruamente las partes en el todo del objeto (teoría de la proporción). Es probable que la tradición haya estado aquí aquejada de un cierto intelectualismo. En este punto sí que me parece, pues, que la teoría tradicional de la proporción como idea perfecta, exacta (desde luego, como proporción numérica - lo que yo suelo llamar "racionalismo matematizante" 44 -, es reductiva, y en tanto que tal, dogmática. Me parece que hay infinitas formas de proporcionalidad, y la 'idea' misma de proporcionalidad debe desbordar el conceptualismo. Por ejemplo, como hemos visto a partir de Danto, es fundamental la 'proporcionalidad' inherente a la relación de las cosas del mundo con las almas, de la que brota el 'sentido' (cosa-sentido) - a las que pertenece la obra de artey que tiene una esencial dimensión histórica. Esto permite entender el carácter abierto de la historia del arte. No es posible, pues, fijar ninguna sección áurea universal en el sentido de un canon estático y cerrado, fijado en una fórmula matemática o en una idea exacta clausurada; y, sin embargo el número de oro tiene su propia validez ontológica e histórica. En todo caso, cuando predomina en el hombre la tendencia al dominio y la seguridad ${ }^{45}$, éste restringe su mirada a lo 'objetivo' de las donaciones, delimita en lo que se da lo que puede dominar — esta actitud ha sido predominante en la modernidad hasta hoy y va muy ligada al método explicativo de la ciencia moderna $^{46}$ - . La mirada que se atiene a lo puramente objetivo es una reducción, en el sentido de una precisión, i.e., se prescinde del plus de donación en muchos sentidos. Para empezar, ya de entrada se da originariamente el exceso de 'la' realidad frente a cualquier 'contenido' objetivo o incluso entitativo, i.e., frente a cualquier clausura óntica o conceptual. Así, la belleza,

\footnotetext{
${ }^{44}$ Víctor Manuel TiRado SAn JuAn, Teoría del arte y belleza en Platón y Aristóteles. La Idea de la estética (Madrid: Ediciones Universidad Eclesiástica San Dámaso, 2012), 54-63.

${ }^{45}$ ZuBIRI, Sobre la esencia, 128-129: "La ratificación de la realidad propia [de la cosa] como (/) algo actualizado en notas que la hacen de fiar es lo que llamamos 'seguridad'". Así, a veces, p. 132 "el hombre busca en las cosas seguridades a que asirse intelectualmente con firmeza. Es posible que, al proceder así, deje de lado grandes riquezas de las cosas".

${ }^{46}$ Edmund Husserl, Die Krisis der europäischen Wissenschaften und die transzendentale Phänomenologie. Zweiter Teil: Die Ursprungsklärung des neuzeitlichen Gegensatzes zwischen physikalistischen Objektivismus und transzendentalem Subjektivismus. Husserliana VI (The Hague: Martinus Nijhoff, 1976), § 9 Galileis Mathematisierung der Natur.
} 
como el bien y la verdad, exceden cualquier mirada humana; ciertamente se dan, pero enigmáticamente, excediendo la mirada. También en esta dirección conectan la idea marioniana de los fenómenos saturados ${ }^{47}$, con la zubiriana de la formalidad de realidad o poderosidad trascendental de lo real impresivamente dada. Esta línea de pensamiento, que rompe con la estrechez de cierta concepción moderna de "lo racional", ha abierto un interesantísimo canal de comunicación entre nosotros y nuestros predecesores medievales, para quienes el misterio atraviesa la realidad entera, lo que les lleva a adoptar una visión alegórico-simbólica del universo ${ }^{48}$. Esto nos hace poner la mirada en otro aspecto que debemos señalar, y que el sesgo antimetafísico del pensamiento dominante hoy pasa por alto: la transcendentalidad como carácter primordial de lo real. En el platonismo (aunque no lo tematiza así) y también en el pensamiento medieval cristiano la transcentalidad reposa sobre la condición radiante del Fundamento, que engendra y atraviesa todo lo real independientemente de cómo se conciba el Fundamento y la 'radiación' misma (como emanación o creación) ${ }^{49}$. Esta irradiación que atraviesa todos

\footnotetext{
${ }^{47}$ Marion, Essai, 29; 31: "hay que dejar al fenómeno surgir desde sí mismo [...] que la donación articule racionalmente los conceptos que dicen el fenómeno tal y como se manifiesta"; Ibidem, 279: "habría que describir las características de un fenómeno que [...] recibiría un exceso (surcroît) de intuición [...] un exceso de intuición, esto es, de la donación sobre la intención [...] un tal fenómeno saturado, sin duda, ya no se dejará constituir en objeto (al menos en el sentido kantiano), pues no va de suyo que la objetividad tenga toda la autoridad para imponer su norma al fenómeno: lo que se muestra se da antes de objetivarse, y no se objetivaría jamás si no se diera primero, aunque no fuera siquiera de un modo elemental y humilde". También, Jean-Luc Marion, De surcroît. Études sur les phénomènes saturés (Paris: PUF-Quadrige 2010; 1 ère ed. 2001).

${ }^{48}$ Johan Huizinga, El otoño de la Edad Media. Studios sobre las formas de la vida y del espiritu durante los siglos XIV y XV en Francia y en los Paises Bajos, trad. de José Gaos (Madrid: Revista de Occidente, 1930), 86-87; UÑa JuÁREZ, Cántico del universo, 54. ECO, Arte y belleza en la estética medieval, 87 y ss. Umberto Eco se ve también aquí, a mi juicio, constreñido por su adscripción a la aún mirada positivista de Popper, y no puede sino ver con sospecha esta mirada simbólica propia del hombre medieval; de hecho la denomina "pansemiosis metafísica" - Umberto Eco. Arte y belleza en la estética medieval, trad. de Helena Lozano Miralles (Barcelona: Debolsillo, 2012), 92 y ss. Evidentemente, la mirada metafísica no pretende ser falsable, porque justamente su objetivo no es dominar la realidad, sino contemplarla, y la contemplación muestra una riqueza insondable que abre infinitas vías. Para sondear la realidad divina, dice Pseudo-Dionisio, intentamos usar "símbolos apropiados". Los nombres de Dios, 9.

${ }^{49}$ En realidad, el concepto de 'transcendental' como propiedad inherente al ser qua ser es una aportación de la escolástica medieval en su intento por combatir el dualismo entre bien y mal de los maniqueos y corrientes gnósticas resaltando la condición originariamente positiva de la creación. El bien y el mal no son co-originarios; por el contrario, el bien, como el unum, la res, el aliquid y el verum, son propiedades inherentes al ente por el mero hecho de ser. Se atribuye a Felipe el Canciller, en su Summa de bono el primer intento de sistematizar el concepto. Cf. Henri Poillon, Le premier traité des propriétés trascendanteles. La «Summa de bono» du Chancelier Philippe, Revue Néoscolastique de Philosophie 42 (1939): 40-77.
} 
los entes se analiza en tres dimensiones transcendentales: la Verdad, la Belleza y el Bien. Aquí la cuestión vuelve a ser la de su 'diferencia' dentro de la indisoluble unidad, pues, Verdad, Belleza y Bondad, siendo inseparables, no son, sin embargo, en mi opinión, mutuamente reducibles (es el misterio de la unidad de simplicidad, que es 'polifónica', pues la irreductible diferencia entre la Verdad, el Bien y la Belleza no impide que sean inseparables y que se interpenetren entre sí $^{50}$ ). El problema aquí ha consistido siempre en reducir un transcendental a otro estableciendo una jerarquía entre ellos. ¿Es la belleza una modulación del bien? ¿Es lo estético un lujo innecesario o una etapa inicial previa al estadio ético...?

La ambigüedad sobre la distinción entre bien y belleza está ya en PseudoDionisio y constituye, como digo, uno de los problemas fundamentales de la estética. Pseudo-Dionisio es coherente con su propia receta metodológica. Puesto que hay un abismo - aunque sea un abismo comunicante- entre Dios y el mundo, no podemos atribuir a Dios en sentido propio determinaciones de los entes del mundo, pero sí podemos atribuírselas en sentido figurado. El ser que Dios comunica a los entes creados es como un rayo; como los rayos del sol, que a la vez que se difunden, iluminan la realidad; pero que en el caso de la Luz primigenia, Bien supremo o Unidad supraesencial, no sólo "ilumina todas las cosas..., las crea, las da vida, las conserva, las perfecciona, es la medida de todos los seres, su tiempo, su número, su orden, su dominio, su causa, su fin" ${ }^{\text {"51 }}$. La metáfora de la luz que irradia el sol en el mundo se convierte en el analogado principal, no sólo para referirse a Dios como creador del mundo (iluminar es crear), sino para conceptuar la fuente de donde mana la belleza concreta de los entes - la Belleza misma; que no será bella al modo de los entes que participan de ella, pero que es la fuente constituyente de las bellezas concretas. No es que el pensamiento medieval dé un salto injustificado a la fe; es que la insuficiencia ontológica del mundo, y la misteriosa articulación de los individuos según propiedades universales - lo cual se puede escudriñar filosóficamenteexige un fundamento extramundano. La cultura actual parece conformarse con propuestas pseudo-metafísicas a la vez que pseudo-científicas (tratar de dar a la teoría del big-bang, etc. sentido metafísico). La belleza que la belleza extramundana comunica al mundo tiene que ver, sin duda con la forma

\footnotetext{
${ }^{50}$ Desde las Investigaciones Lógicas Husserl había mostrado diferentes modos de 'ser parte'; por ejemplo, parte separable (Stück), o parte inseparable o abstracta (unabhängiger Teil). Las partes abstractas se interpenetran (sich durchdringen).

${ }^{51}$ Pseudo-Dionisio, Los nombres de Dios, 33.
} 
-Zubiri la denomina "talidad", función transcendental que hace que la realidad sea realidad tal, i.e., esta o esa realidad concreta-. La forma es la que determina la unidad esencial del individuo, o, inversamente, la unidad es la forma: la forma de unidad. Cuanto más acabada sea esa unidad, más simplicidad habrá en la riqueza de notas que constituyen la esencia de una cosa. Esta unidad esencial, puede entrar en respectividad con la inteligencia, con la voluntad, o con el sentimiento; la respectividad intelectiva de la cosa es la verdad; su respectividad volitiva, la bondad; y su respectividad sentimental, la belleza de la 'cosa'.

Pero la metáfora de la luz no sólo se aplica en sentido transcendental fundamental (la Luz como fuente de realidad), sino que se aplica también de un modo más restringido y particular como estética de la visión y del color. Al menos desde Platón se sitúa la vista como el sentido más elevado y cercano al intelecto. Plotino lo aludía en una de sus definiciones de la belleza: "una proporción armónica de las partes entre sí y con el todo, con la adición de un colorido agradable" 52 ; y lo mismo San Agustín: "Toda belleza del cuerpo es conveniencia armoniosa de sus partes, con cierto agrado o suavidad de color" 53 .

No podemos entrar ya aquí en esta interesante cuestión; en realidad corresponde a la estética especial de la visión que, efectivamente, en el medioevo adquiere una importancia decisiva, pues, ciertamente, la luz mundana revela los colores ${ }^{54}$. La estética contemporánea tiende a combatir esta supuesta primacía de la visión poniendo en valor los demás sentidos y ampliando así el campo de lo estético al gusto, el olfato y el tacto, tema ya en sí mismo difícil y de gran interés. Las innovaciones técnicas han posibilitado formas artísticas que integran diversos ámbitos estéticos, como, por ejemplo, el cine, que, de alguna manera, integra literatura, artes visuales y música. Los pensadores medievales hacen también de la estética del color una interpretación ontológica que excede la estética de las artes visuales desarrollando metafísicamente los conceptos de "esplendor" y "resplandor" 55 . Preci-

\footnotetext{
${ }^{52}$ Cf. supra nota 20.

${ }^{53}$ San Agustín, La ciudad de Dios, XXII, 19, 2.

${ }^{54}$ Cf. el interesante trabajo de Adrien Pradier Sebastián, La estética de la luz en la Edad Media. De Ps. Dionisio Areopagita a Roberto Grosseteste. Salamanca: Universidad de Salamanca (tesis doctoral) 2015. GREDOS. Gestión del Repositorio Documental de la Universidad de Salamanca. El acceso 28 de diciembre de 2020. https://gredos.usal.es/handle/10366/132918.

${ }^{55}$ Por ejemplo, Alberto Magno, Comentario, 182 b. 82 b.: (182 b) "lo bello encierra en su razón tres cosas, a saber, (1) el esplendor de la forma sustancial o accidental sobre las partes proporcionadas y acabadas de la materia, como el cuerpo se llama bello por el resplandor del color sobre los miembros proporcionados y esto es como una diferencia específica que realiza la razón de
} 
samente San Alberto, aun advirtiendo de la diferencia entre el concepto de proporción, que proviene de la categoría de cantidad, y del de claridad (perteneciente al color y la luz), que proviene de la categoría de cualidad, señala la doble posible interpretación de la estética de la luz: "tal como se requiere para la belleza del cuerpo que haya una debida proporción de los miembros y que el color destelle en ellos, de tal manera que, si faltare una de ambas cosas, el cuerpo no sería bello, así también se requiere para la noción universal de belleza una proporción de ciertas cosas entre sí, ya sean partes, ya potencias, ya cualesquiera cosas en las cuales destelle la claridad de la forma" ${ }^{26}$. También aquí abre, pues, la especulación medieval enormes posibilidades para una nueva ontología de lo real ${ }^{57}$.

No puedo ya alargar más este fragmentario ensayo. Hay dos asuntos que me interesan particularmente y que ya no puedo tratar aquí como merecen. Uno lo he esbozado: la cuestión de la supeditación de la belleza a la bondad. Ya San Alberto introduce matizaciones muy importantes para diferenciarlas. Santo Tomás las desarrolla abriendo una vía genial, que, sorprendentemente, constituye, a mi juicio, la base que Kant explota para desarrollar su estética en la Crítica del Juicio. El punto de arranque es la distinción que hace San Alberto entre la cosa considerada en sí misma (ordo essendi) y la cosa en relación al hombre que la aprehende (ordo cognoscendi). En la primera perspectiva, en lo que se refiere a la cosa misma, tienden a sostener tanto San Alberto como Santo Tomás, que bondad y belleza se identifican: "La Belleza y el Bien son la misma cosa en el sujeto al que cualifican (in subiecto), porque se fundan sobre la misma realidad (super eadem rem), esto es, sobre la forma del ser determinado" ${ }^{98}$. La cosa es la cosa, la que es de suyo. En este sentido sería 'neutra', y este 'de suyo' sería el que revela la inteligencia. De aquí la primacía de la inteligencia, porque revela lo que las cosas reales son en sí mismas. Y, sin embargo, no cabe identificar la cosa y su verdad, pues la verdad acontece en la respectividad de la cosa con la inteligencia; sin inteligencia no hay verdad, aunque hubiere cosa; es decir, de alguna manera, la realidad en sí misma considerada, in subiecto, presupone ya estar situado

lo bello; (2) el atraer hacia sí el deseo y esto lo posee en cuanto es bueno y fin (...y) (3) el congregar todas las cosas".

${ }^{56}$ Alberto Magno, Comentario, 185 b 25.

${ }^{57}$ Xavier Zubiri lo desarrolla incorporando el concepto metafísico de "dimensión", que se añade al de "categoría" y "propiedad" de una sustancia. Para un desarrollo de esta categoría en estética cf. Víctor Manuel Tirado San Juan, Esencia y dimensionalidad de lo estético. Lo estético (Madrid: Ediciones Universidad Eclesiástica San Dámaso, 2020), 21-49.

${ }^{58}$ Tomás de Aquino, Summa Theologiae, I, q. 5, a. 4, ad $1 \mathrm{~m}$. 
en el ordo cognoscendi. Esto es lo que el genio que Husserl nos mostró señalando, en la línea de San Agustín, la primacía metodológica del espíritu, de la vida de conciencia, como condición de posibilidad de acceso al $\operatorname{ser}^{59}$. En todo caso, tanto Alberto como Tomás parecen situar la diferencia entre la bondad y la belleza de las cosas en la específica relación en que ella entra con el espíritu: si la cosa hace relación a la 'voluntad' como apetecible, entonces revela su condición de 'buena'. Pero ¿revela su condición de bella, habida cuenta de que estos pensadores sólo reconocen dos facultades espirituales: intelecto y voluntad? ${ }^{60}$. San Alberto vuelve a la hipótesis ontológica de la proportio extraída de la claritas: "lo bello añade a esto [a lo verdadero y al bien] cierto resplandor y claridad sobre ciertas cosas proporcionadas" $"$. Pero la pregunta sigue en pie: ¿con qué facultad captamos dicho resplandor, claridad y proporción? Si de nuevo es la inteligencia, entonces la belleza será la verdad y la experiencia estética, como a la postre defendía Platón, un tipo de intelección. Santo Tomás, sin postular una tercera facultad del espíritu (como ya hace Kant en la Crítica del Juicio - de aquí que sea la tercera crítica: la 'tercera raíz común'-), abre este horizonte, pues diferencia la bondad y la belleza de los entes en función de una forma particular de actualizarse éstos en las facultades del alma: "[aunque belleza y bondad no son refieren a propiedades distintas en la cosa] difieren por su definición (ratione differunt). Porque el bien se refiere formalmente al apetito de lo real: bien, en efecto, es lo que todos apetecen, y por tanto se sitúa en el orden de los fines [voluntad], puesto que el deseo o el apetito son, por decirlo así, como una tensión hacia la realidad. La belleza, por el contrario, se define en función de las facultades de conocimiento: en efecto, se dice bello aquello cuya vista deleita. Es por esto por lo que la belleza consiste en la relación conveniente (de la forma a la conciencia), ya que la sensibilidad no

\footnotetext{
${ }^{59}$ Por eso dice Santo Tomás que en orden a la verdad tiene primacía el entendimiento sobre la cosa: "Como lo verdadero está en el entendimiento en cuanto que hay conformidad entre éste y lo conocido, es necesario que la razón de verdadero derive del entendimiento a lo conocido". Summa Theologiae, I; I, C. 16, art. $1^{\circ}, 224$ b.

${ }^{60}$ Alberto Magno, Comentario, 181 b 7: "La primera procesión que se da en la mente — dice San Alberto - se produce de acuerdo con la aprehensión de lo verdadero. Después, eso verdadero se enciende y es tomado en su razón de bueno y, de tal manera, el deseo es movido a continuación hacia él. En efecto, conviene que al movimiento del deseo le anteceda una doble aprehensión: una que está en el entendimiento especulativo, que versa sobre lo verdadero mismo de manera absoluta, y otra que está en el entendimiento práctico por extensión de lo verdadero hasta la razón de bueno; en ese momento se dará el movimiento del deseo hacia el bien [...] el deseo no se movería, si no fuera dirigido mediante una aprehensión precedente".

${ }^{61}$ Alberto Magno, Comentario, 186 b 5.
} 
disfruta más que las proporciones convenientes de las cosas que son análogas a su propia armonía. Por otra parte la sensibilidad es cierto ordenamiento (ratio) como toda facultad de conocimiento. Y puesto que el conocer se hace por asimilación de una representación y la representación refleja la forma, la belleza se sitúa en sentido estricto y propio en el orden de la causa formal (y no de la causa final)"62. Bello es, pues, lo que a la 'vista' place. Kant no hará sino adaptar esto a su filosofía de la subjetividad transcendental. La belleza es ese peculiar placer que el sujeto transcendental experimenta ante representaciones que poner en relación armónica las facultades cognoscitivas humanas en libre juego. En este contexto, la cuestión de la irrealidad en la vida estética cobrará cada vez mayor protagonismo.

El otro problema que me interesa tiene que ver con este doble lugar en el que acontece la belleza: los entes del mundo en su aparecer a las conciencias. Pero ya no puedo tratarlo aquí.

\section{BIBLIOGRAFÍA}

Agustín (San). De Trinitate. Escritos apologéticos (2. ${ }^{\circ}$ ): La Trinidad. Madrid: BAC, 2006.

Agustín (San). La ciudad de Dios, vol. II. Madrid: BAC, 1988.

Alberto Magno (San). Comentario a "De los nombres divinos" de Dionisio Areopagita. Magni Ordinis Fratrum Praedicatorum Super Dionysium De divinis nominibus. Münster 1972: Paulus Simon (Monasterii estfalorum: In aedibus Aschendorff) p. 180, v. 82 - p. 197, v. 26 [§§ 71-94] (Traducción de David Torrijos).

Aristóteles. Metafísica. Traducción de Valentín García Yebra. Madrid: Gredos, 1998.

Benjamin, Walter. Das Kunstwerk im Zeitalter seiner technischen Reproduzierbarkeit. Drei Studien zur Kunstsoziologie. 34. Aufl. Frankfurt am Main: Suhrkamp, 2015 (1. Aufl. 1935). Traducción española: La obra de arte en la época de su reproductibilidad técnica. Traducción de Alfredo Brotons Muñoz. Madrid: Abada, 2018).

Chaignet, Anthelme. Pythagore et la philosophie pythagoricienne. Contenant les fragments de Philolaüs et Archytas. Paris: Didier et Cie, 1873.

Danto, Arthur. El abuso de la belleza: La estética y el concepto del arte. Barcelona: Ediciones Paidós 2011.

DickI, George. Introduction to Aesthetics: An Analytic Approach. New York: Oxford University Press, 1997.

Eco, Umberto. Arte y belleza en la estética medieval. Traducción de Helena Lozano Miralles. Barcelona: Debolsillo, 2012.

Eco, Umberto. "Dieci mode di sognare el Medioevo". En Umberto Eco. Scritti sul pensiero medievale, 1093-1108. Milano: Bompiani/RCS Libri 2016.

HeidegGer, Martin. Sein und Zeit. Tübingen: Max Niemeyer Verlag, 1986.

\footnotetext{
${ }^{62}$ TomÁs de Aquino, Summa Theologiae, I, q. 5, a. 4, ad 1m. Los corchetes son míos.
} 
Huizinga, Johan. El otoño de la Edad Media. Studios sobre las formas de la vida y del espíritu durante los siglos XIV y XV en Francia y en los Países Bajos. Traducción de José Gaos. Madrid: Revista de Occidente, 1930.

Husserl, Edmund. Die Krisis der europäischen Wissenschaften und die transzendentale Phänomenologie. Zweiter Teil: Die Ursprungsklärung des neuzeitlichen Gegensatzes zwischen physikalistischen Objektivismus und transzendentalem Subjektivismus. Husserliana VI. The Hague: Martinus Nijhoff, 1976.

Kant, Immanuel. Crítica del juicio [Kritik der Urteilskraft]. Traducción de Manuel García Morente. Madrid: Espasa Calpe, 1981.

Kant, Immanurl. Kritik der Urteilskraft. Einleitung 4. Sttutgart: Reclam 1986 (Traducción de Garcia Morente. Madrid: Espasa Calpe, 1981).

Marenborn, John. "Medieval and Renaissance Aesthetics". En A Companion to Aesthetics, edited by Stephen Davies, Kathleen Marie Higgins, Robert Hopkins y Robert Stecker, David E. Cooper, 22-28. Malden/Oxford: Blackwell 2009.

Marion, Jean-Luc. Étant donné. Essai d'une phénoménologie de la donation. Paris: PUF, 1997

Marion, Jean-Luc. De surcroît. Études sur les phénomènes saturés. Paris: PUF-Quadrige, 2010.

O'Connell, Robert J. Art and the Christian Intelligence in Saint Augustin. Cambridge: Harvard University Press, 1978.

Platón. Diálogos, vol. III: Fedro. Madrid: Gredos, 2020.

Platón. Diálogos, vol. I: Hipias mayor. Madrid: Gredos, 2020.

Plotino. Sobre la belleza. Traducción de Agustín López y María Tabuyo. Barcelona: El Barquero, 2007.

Polllon, Henri. "Le premier traité des propriétés trascendanteles. La «Summa de bono» du Chancelier Philippe". Revue Néoscolastique de Philosophie 42 (1939): 40-77.

Pradier Sebastián, Adrien. La estética de la luz en la Edad Media. De Ps. Dionisio Areopagita a Roberto Grosseteste. Salamanca: Universidad de Salamanca (tesis doctoral) 2015. GREDOS. Gestión del Repositorio Documental de la Universidad de Salamanca. El acceso 28 de diciembre de 2020. https://gredos.usal.es/handle/10366/132918.

Pseudo-Dionisio. Los nombres de Dios. En Obras completas. BAC: Madrid, 2007.

Ratzinger, Joseph. Discurso en la Universidad de Ratisbona del 12 de septiembre de 2006: "Fe, razón y universidad. Recuerdos y reflexiones". La Santa Sede. El acceso 28 de diciembre de 2020. http://www.vatican.va/content/ benedict-xvi/es/speeches/2006/september/ documents/hf_ ben-xvi_spe_20060912_university- regensburg.html.

Svoboda, Karel. La estética de San Agustín y sus fuentes. Traducción de Luis Rey Altuna. Madrid: Agustinus 1958.

Tirado San Juan, Víctor Manuel. Teoría del arte y belleza en Platón y Aristóteles. La Idea de la estética. Madrid: Ediciones Universidad Eclesiástica San Dámaso 2012.

TiRado San Juan, Víctor Manuel. Esencia y dimensionalidad de lo estético. Lo estético. Madrid: Ediciones Universidad Eclesiástica San Dámaso, 2020.

Tomás de Aquino (Santo). Summa Theologiae. I: Prima pars. Madrid: BAC, 1994.

Torrijos CAstrillejo, David. "Alberto Magno y las bellas artes". De Medio Aevo 14 (2020): $117-129$.

Trapé, Agostino. San Agostino. L'uomo, il pastore, il mistico. Fossano: Edizione l'Esperienze, 1976.

Uña JuÁrez, Augustin. Cántico del universo. La estética de San Agustín. Madrid: Universidad Complutense de Madrid, 1999. 
ZuBIRI, Xavier. Cursos Universitarios II. Madrid: Alianza Ed., 2010.

ZuBIRI, Xavier. Sobre la esencia. Madrid: Alianza Editorial \& Fundación Xavier Zubiri, 2008.

\title{
UNA MIRADA A LA ESTÉTICA MEDIEVAL AL CONTRALUZ DE LA ESTÉTICA CONTEMPORÁNEA
}

\author{
Resumen
}

Autor de este ensayo trata de mostrar el valor de la estética medieval poniéndola en diálogo con algunos aspectos fundamentales de la estética contemporánea. Se esboza una descripción de aquellas cuestiones que más contrastan con la cultura actual: la predominancia en la Edad Media de la fe religiosa y la fusión con la tradición del pensamiento griego en una perspectiva metafísica, de la que se parte en la elaboración de la teoría estética, desarrollando una teoría ontológica de la belleza y del arte. Por el contrario, la época actual, muy deudora aún de la modernidad, está instalada en una posición de enorme fragilidad metafísica y de fe religiosa, restringiendo en exceso la razón a la racionalidad científica. En este sentido, el medioevo puede inspirarnos en la tarea, ya emprendida por ciertas corrientes de la fenomenología, de ampliar la razón. En este marco se analizan las dificultades de la estética medieval para concebir claramente la diferencia entre la belleza y el bien, cosa que se ha hecho mejor en las líneas modernas que no han perdido lo transcendental, desde Immanuel Kant a Xavier Zubiri. Se bareman diversas concepciones de la Edad Media, de la mano fundamentalmente de Umberto Eco, y sin idealizarla, se destacan no obstante valores importantes en ella. Se defiende la tesis de que no es posible renunciar completamente a la teoría de la proporción, sino que debe ampliarse sobre la base de una ontología más rica, que, junto a las cosas-reales del mundo, tenga en cuenta las cosas-sentido, de acuerdo a la propuesta de Xavier Zubiri. Esto permite asumir críticamente la ampliación del horizonte estético (la apertura de los valores estéticos) propia del contemporáneo sin caer en el nihilismo.

Palabras claves: estética medieval; estética contemporánea; ampliación de la razón; teoría de la proporción; canon estético abierto.

\section{A LOOK AT MEDIEVAL AESTHETICS UNDER THE BACKLIGHT OF CONTEMPORARY AESTHETICS}

\section{Sum mary}

The Author of this essay tries to show the value of medieval aesthetics by putting it in dialogue with some fundamental aspects of contemporary aesthetics. A description of those issues that most contrast with current culture is outlined: the predominance in the Middle Ages of religious faith and its fusion with the tradition of Greek thought in a metaphysical perspective, in order to elaborate the aesthetic theory, developing an ontological theory of beauty and art. On the contrary, the current era, still very indebted to modernity, is installed in a position of enormous metaphysical fragility and religious faith, excessively restricting reason to scientific rationality. In this sense, the Middle Ages can inspire us in the quest, already undertaken by certain currents of phenomenology, of expanding reason. In this framework, the difficulties of medieval aesthetics in order to conceive clearly the difference between beauty and good are analysed, then it has been something that has been done better in modern lines that have not lost the transcendental, from Immanuel Kant to Xavier Zubiri. Various conceptions of the Middle Ages are asserted, fundamentally from the hand of Umberto Eco, and without idealizing it, important values stand 
out in it nonetheless. The thesis is defended that it is not possible to completely renounce the theory of proportion, but that it must be expanded on the basis of a richer ontology, which, together with the 'real-things' of the world, takes into account the 'sense-things', according to the proposal of Xavier Zubiri. This allows us to critically assume the expansion of the aesthetic horizon (the opening of aesthetic values) typical of the contemporary without falling into nihilism.

Key words: medieval aesthetics; contemporary aesthetics; expansion of reason; proportion theory; open aesthetic canon.

\section{SPOJRZENIE NA ESTETYKĘ ŚREDNIOWIECZNĄ W ŚWIETLE ESTETYKI WSPÓŁCZESNEJ}

\section{Streszczenie}

Autor tego eseju stara się ukazać wartość estetyki średniowiecznej poprzez dialogiczne zestawienie jej zasad z podstawowymi aspektami estetyki współczesnej. Dano zarys tych zagadnień, które najbardziej kontrastują z obecną kulturą: dominacja wiary religijnej w średniowieczu i fuzja z tradycją myśli greckiej w perspektywie metafizycznej, z której ta teoria jest rozwijana, a z niej ontologiczna teoria piękna i sztuki. Z drugiej strony obecna epoka, wciąż pełna zobowiązań wobec nowoczesności, znajduje się w stanie ogromnej metafizycznej kruchości, w tym w odniesieniu do wiary religijnej, nadmiernie ograniczając rozum do racjonalności naukowej. W tym sensie średniowiecze może zainspirować nas do ekspansji rozumu, co zostało już podjęte przez niektóre nurty fenomenologii. W tym kontekście analizuje się trudności średniowiecznej estetyki, aby wyraźnie wyobrazić sobie różnicę między pięknem a dobrem, coś, co zostało już zrobione w pewnych nowoczesnych nurtach, które nie wyzbyły się transcendencji — od Immanuela Kanta po Xaviera Zubiriego. Ukazane są różne koncepcje średniowiecza, głównie autorstwa Umberto Eco, z których bez idealizowania wyłaniają się ważne wartości. Broni się tezy, że nie można całkowicie wyrzec się teorii proporcji, ale należy ją rozwinąć w oparciu o bogatą ontologię, która wraz $\mathrm{z}$,rzeczywistymi rzeczami” świata uwzględnia rzeczy zmysłowe, według propozycji Xaviera Zubiriego. Pozwala to krytycznie założyć rozszerzenie horyzontu estetycznego (otwarcie wartości estetycznych) typowe dla współczesności bez popadania w nihilizm.

Przełożyt Stanistaw Sarek

Słowa kluczowe: estetyka średniowieczna; estetyka współczesna; ekspansja rozumu; teoria proporcji; otwarty kanon estetyczny. 